\title{
Wait time for endoscopic evaluation at a Canadian tertiary care centre: Comparison with Canadian Association of Gastroenterology targets
}

\author{
Derek Yu MD ${ }^{1}$, Wilma M Hopman $\mathrm{MA}^{2}$, William G Paterson $\mathrm{MD}^{1}$
}

D Yu, WM Hopman, WG Paterson. Wait time for endoscopic evaluation at a Canadian tertiary care centre: Comparison with Canadian Association of Gastroenterology targets. Can J Gastroenterol 2008;22(7):621-626.

BACKGROUND: In recent years, there has been considerable concern regarding wait times for Canadian health care, which led the Canadian Association of Gastroenterology (CAG) to develop specific wait time targets.

OBJECTIVES: To quantify wait times for endoscopic procedures at a tertiary care centre and correlate these with clinical presentation, impact on quality of life (QOL) and final diagnosis; and to determine how well the CAG wait time targets are being met.

METHODS: Patients completed a 12-item questionnaire regarding wait times and their impact on QOL. A blind review was performed of the endoscopic results, with a specific focus on correlating wait time with a final diagnosis of serious and treatable diseases.

RESULTS: The average total wait time for the 417 participants in the present study was 229 days; $78.6 \%$ did not meet CAG wait time targets. The wait time for screening colonoscopy was longer, and the proportion of patients meeting wait time targets was significantly smaller, than for patients referred with iron deficiency anemia or a positive fecal occult blood test result. The 41 patients deemed to have a high-impact diagnosis established by endoscopy had a median wait time of 115 days, and only $23.5 \%$ met wait time targets. Overall, $38.4 \%$ of patients believed that their wait was too long, $13.9 \%$ missed school or work in the preceding month because of gastrointestinal symptoms and $23 \%$ reported being very worried about having a serious disease.

CONCLUSIONS: The majority of patients waiting for endoscopy did not meet CAG wait time targets, with the screening colonoscopy group faring the worst. Many of these patients await a definitive diagnosis of serious diseases that negatively impact QOL.

Key Words: Canadian Association of Gastroenterology wait time targets; Endoscopic procedures
Le temps d'attente avant d'obtenir une évaluation endoscopique à un centre de soins tertiaires canadien par rapport aux cibles de l'Association canadienne de gastroentérologie

HISTORIQUE : Ces dernières années, on s'est beaucoup inquiété des temps d'attente pour obtenir des soins au Canada, ce qui a incité l'Association canadienne de gastroentérologie (ACG) à établir des cibles de temps d'attente précises.

OBJECTIFS : Quantifier les temps d'attente pour obtenir une endoscopie dans un centre de soins tertiaires et corréler ces résultats avec la présentation clinique, les répercussions sur la qualité de vie (QDV) et le diagnostic définitif, et déterminer à quel point les cibles de temps d'attente de l'ACG sont respectées.

MÉTHODOLOGIE : Les patients ont rempli un questionnaire de 12 questions au sujet des temps d'attente et de leurs répercussions sur la QDV. Les auteurs ont procédé à une analyse en aveugle des résultats endoscopiques afin de corréler les temps d'attente avec le diagnostic définitif de maladie grave et traitable.

RÉSULTATS : En moyenne, le temps d'attente total des 417 participants à la présente étude était de 229 jours, dont 78,6 \% ne respectaient pas les cibles de temps d'attente de l'ACG. Le temps d'attente pour obtenir des coloscopies de dépistage était plus long, et la proportion de patients respectant les cibles de temps d'attente était beaucoup plus faible que pour ceux qui étaient aiguillés en raison d'une anémie ferriprive ou d'une recherche positive de sang occulte dans les selles. Les 41 patients réputés avoir un diagnostic à fort impact établi par endoscopie avaient eu un temps d'attente médian de 115 jours, et seulement 23,5\% respectaient les cibles de temps d'attente. Dans l'ensemble, 38,4\% des patients trouvaient avoir attendu trop longtemps, 13,9 \% ont dû s'absenter de l'école ou du travail dans les mois précédents en raison de symptômes gastro-intestinaux et 23 \% ont déclaré beaucoup s'inquiéter de souffrir d'une maladie grave.

CONCLUSIONS : La majorité des patients en attente d'une endoscopie n'avaient pas profité des cibles de temps d'attente de l'ACG, le groupe ayant subi une coloscopie de dépistage attendant beaucoup plus longtemps. Bon nombre de ces patients attendent un diagnostic définitif de maladie grave, ce qui a des répercussions négatives sur leur QDV.
Cxcessive wait times for health care have been and con- tinue to be a major issue in the Canadian health care sector (1). Demand for health care services continues to increase as the Ontario population ages, diagnostic tests improve and advances in technology make more conditions treatable (2).
In response to growing public concern, the federal government announced a shared agenda for renewal of health care in Canada, including timely access to quality care, with a specific emphasis on better management of wait times and the measurable reduction in wait times where they are longer

${ }^{1}$ Gastrointestinal Diseases Research Unit and Department of Medicine; ${ }^{2}$ Clinical Research Centre, Kingston General Hospital and Department of Community Health and Epidemiology, Queen's University, Kingston, Ontario

Correspondence: Dr William G Paterson, Queen's University, 166 Brock Street, Kingston, Ontario K7L 5G2. Telephone 613-544-3400

ext 3376, fax 613-544-3114, e-mail patersow@hdh.kari.net

Received for publication April 11, 2008. Accepted April 13, 2008 
than medically acceptable (3). Although the public and providers are concerned about wait times, no one is certain how long the majority of people wait for most procedures. Ontario does not have valid and reliable wait time information to help determine where problems exist, how serious they are and what to do about them (4).

The Canadian gastroenterology community has long been concerned about access to digestive health care services, including delays for initial specialist consultation, as well as endoscopic and other diagnostic services. These delays are even more concerning given the prevalence of digestive problems. In Canada, digestive diseases are responsible for a major economic burden and account for 15\% of the total direct economic Canadian health care costs, exceeding those for mental, cardiovascular, respiratory and central nervous system diseases (5). Therefore, the Canadian Association of Gastroenterology (CAG) has instituted a number of important projects designed to address this problem, including the development of evidence- and expertise-based recommendations for medically appropriate maximal wait times for consultation and procedures by a digestive disease specialist (6).

A previous study (7) investigating wait times for gastrointestinal (GI) consultation in Canada, found that wait times varied widely across the country, with many patients being dissatisfied with their wait times. To gather an accurate understanding of access limitations in gastroenterology, the timing of follow-up investigations, including diagnostic procedures, should be incorporated when wait times are analyzed. The objectives of the present study were to quantify wait times for GI endoscopic procedures at a tertiary care centre and correlate these with the clinical presentation, impact on quality of life (QOL) and final diagnosis; and to compare actual wait times with CAG benchmark wait times to identify limitations in access to digestive health care in Canada.

\section{METHODS}

The present study was approved by the Research Ethics Board at Queen's University (Kingston, Ontario). It was conducted at an outpatient gastroenterology centre in a tertiary health care centre in southeastern Ontario, with a referral population of more than 500,000 people. Over a 26 -week period (December 2005 to June 2006), patients were asked to complete a questionnaire (Appendix A) before undergoing an outpatient esophagogastroduodenoscopy, colonoscopy and/or flexible sigmoidoscopy. The questionnaire was distributed, along with a patient information sheet and consent form, by an endoscopy nurse when patients arrived for their procedure. An attending gastroenterologist was available, if required, to answer patient questions concerning the study. The questionnaire consisted of 12 questions regarding the type of procedure, indication for the procedure, wait time, patient perspective on wait time, patient understanding of diagnosis, time missed from school or work and the impact of wait time on QOL. The initial nine questions required patients to select an answer from a listed selection of choices. The remaining three questions concerning wait time impact on QOL used a seven-point Likert response scale. Patients were asked to indicate the level of impact that wait time had on various aspects of their QOL because of their ongoing GI symptoms. For the purpose of the present study, a score of 5 or more indicated that the wait time had a significant impact on their patients' QOL.
Wait time was defined as the period from when the patient was initially referred for gastroenterology consultation (as defined by the date that the referral was faxed) to the date of the endoscopic procedure. Initial consultation dates were determined by a retrospective chart review. To determine a diagnosis, a blind review of the endoscopic and pathological results, acquired from the computerized patient records system, was subsequently performed.

To establish the impact of a specific diagnosis, a panel of five gastroenterologists was provided with the reason for referral and the gross endoscopic and pathological results, and asked to rate the level of impact of the diagnosis with respect to management change, whereby an intervention could change the patient's QOL; and the impact on the prognosis. Using a three-point rating system (low, medium, high), a diagnosis was considered to be of high impact if four of five gastroenterologists on the panel rated that diagnosis as having a high impact (Appendix B).

\section{Statistical analysis}

Data were entered into a Microsoft Office Excel spreadsheet (Microsoft Corporation, USA) and imported into SPSS version 12.0 for Windows (SPSS Inc, USA) for analysis. The main reason for referral was categorized into one of 14 reasons, while the pathology findings were grouped into 18 categories. Descriptive analyses (means, SDs, medians, quartiles and frequencies) were completed for the entire sample, as well as the subset referred for screening or surveillance, and iron deficiency anemia or a positive fecal occult blood test (FOBT) result. Actual wait times were graphed and compared with the CAG target wait times. Waiting time for those referred for screening was compared with waiting time for those referred for anemia or a positive FOBT result using a nonparametric Mann-Whitney U test.

\section{RESULTS}

From December 19, 2005 to June 22, 2006, 431 patients who underwent an endoscopic procedure participated in the study questionnaire. This represents $22 \%$ of all patients undergoing endoscopy by the gastroenterology service during that period. Ten participants were excluded based on unavailable information from the electronic patient clinical records at the time of data collection. Three participants were excluded because the questionnaire received was incomplete. One participant was excluded because the patient was followed by a general surgeon rather than a gastroenterologist.

\section{Overall study population}

Of the 417 participants (median age 55 years, mean age 52.8 years, range 17 to 88 years; 183 men and 234 women) included in the analysis, 249 (59.7\%) underwent colonoscopy, 89 (21.3\%) underwent upper endoscopy, 54 (12.9\%) underwent flexible sigmoidoscopy, 24 (5.8\%) underwent colonoscopy plus upper endoscopy and one $(0.2 \%)$ underwent upper endoscopy plus flexible sigmoidoscopy.

Two hundred seventy-seven patients $(66.4 \%)$ had a documented referral to a gastroenterologist, 113 (27.1\%) were patients who were already followed by a gastroenterologist and $27(6.5 \%)$ had no documentation of initial referral. Of the 277 participants with documented referral, the mean and median total wait times were 229 and 180 days, respectively, with a range of nine to 752 days (Figure 1). 


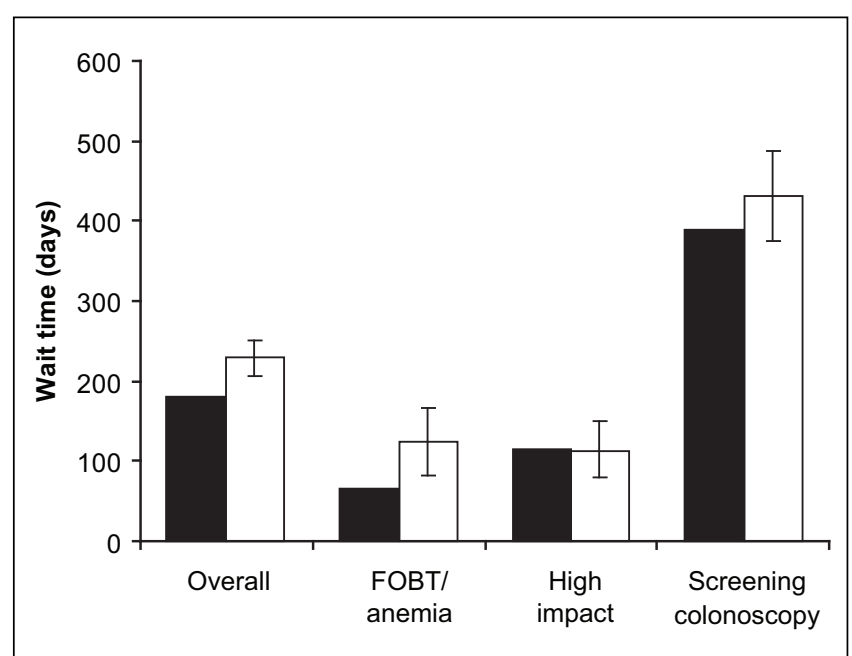

Figure 1) Median (black bars) and mean (white bars) wait times of patients with documented referrals. Mean wait times include 95\% CIs. The positive fecal occult blood test (FOBT)/anemia group had the shortest wait times, while screening colonoscopy patients had the longest wait times $(P<0.001)$

Patient perspective on wait time: Regarding the patient perspective on wait time, $10.6 \%$ rated the wait as "far too long", $27.8 \%$ as "somewhat too long", $56.4 \%$ as "about right", $1 \%$ as "somewhat too short" and $1.7 \%$ as "far too short".

Wait time impact on QOL: Of the 374 patients who were attending school or working, 52 (13.9\%) reported having missed at least one day of work or school in the previous month because of ongoing GI symptoms. A substantial number of patients reported that their GI symptoms adversely affected their QOL while awaiting endoscopy. A score of 5 or more on the seven-point Likert scale was recorded by $23 \%$, $20 \%$ and $13 \%$ of patients with respect to degree of worry about having a serious diagnosis, GI symptoms interfering with social function and GI symptoms interfering with their ability to perform activities of daily living, respectively (Figure 2).

CAG targets: Based on CAG wait time targets and the corresponding presenting complaint of the participant, 58 of $271(21.4 \%)$ newly referred participants met their CAG targets. Six of the 271 new referrals had presenting complaints that were not included in the CAG wait time target recommendation and therefore were not included in the data analysis (Figure 3).

\section{Screening and surveillance colonoscopy subgroup}

Sixty-one patients underwent a colonoscopy for the first time for initial screening purposes. Of the 58 participants with a documented referral, the mean wait time was 428 days and the median wait time was 380 days, with a range of 15 to 752 days (Figure 1).

Sixty-one patients underwent a colonoscopy for surveillance purposes. Of the 45 patients who had documented recommendation dates for a repeat procedure, only 12 had a repeat procedure within six months of the recommended date. The mean and median wait times following the recommended date for a repeat endoscopy were 303.8 and 225 days, respectively.

Patient perspective on wait time: In this subgroup of patients,

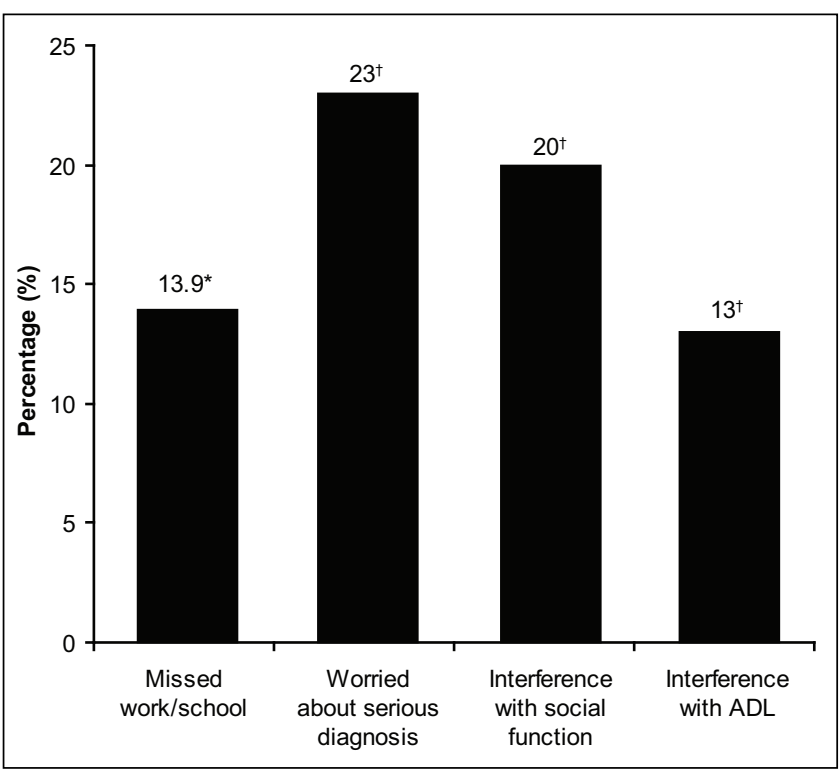

Figure 2) Quality of life assessment in the total population waiting for endoscopic procedures. *Missed at least one day of work or school in the preceding month because of gastrointestinal symptoms; ${ }^{\dagger}$ Scored 5 or more on the seven-point Likert scale. A significant proportion of patients waiting for an endoscopic procedure reported a high degree of worry related to their gastrointestinal condition, or that their gastrointestinal symptoms were adversely affecting their quality of life. ADL Activities of daily living

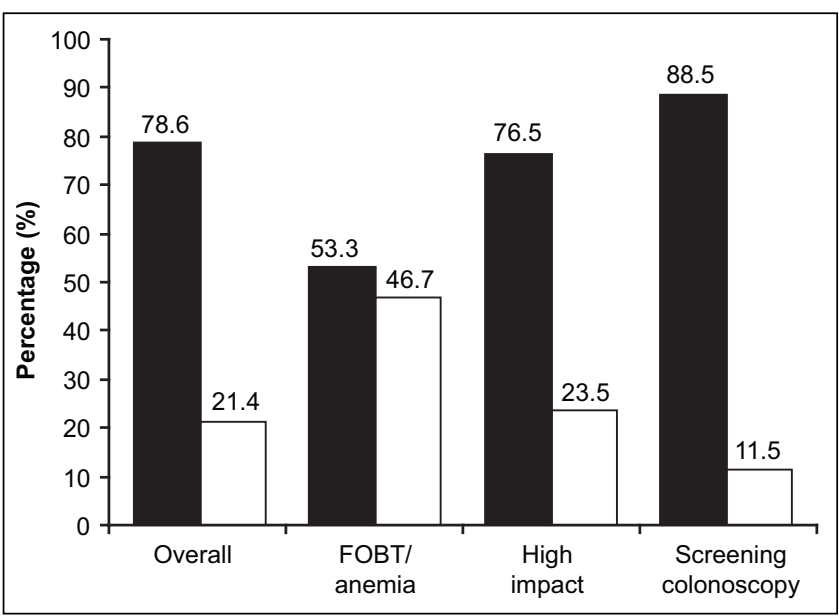

Figure 3) The Canadian Association of Gastroenterology (CAG) target wait times not met in the present study are indicated by black bars, while the CAG target wait times met are indicated by white bars. The majority of patients waiting for gastrointestinal endoscopic procedures did not meet CAG wait time targets, with the screening colonoscopy group faring the worst. FOBT Fecal occult blood test

$15 \%$ of the patients rated the wait as "far too long", $31.7 \%$ as "somewhat too long", $48.3 \%$ as "about right" and 1.7\% as "far too short”.

CAG targets: Based on CAG wait time targets for screening endoscopies in a newly referred patient, seven of $61(11.5 \%)$ met their CAG targets (Figure 3). 


\section{Iron deficiency anemia and positive FOBT result subgroup} Thirty-eight of the 417 participants underwent various endoscopic procedures for evaluation of iron deficiency anemia and/or a positive FOBT result. These included 19 colonoscopies, two flexible sigmoidoscopies, five upper endoscopies and 12 colonoscopies plus upper endoscopies. Of the 30 participants with a documented referral, the mean wait time was 125 days and the median wait time was 65 days, with a range of nine to 365 days (Figure 1).

Patient perspective on wait time: In this subgroup of patients, $5.3 \%$ rated the wait as "far too long", $7.9 \%$ as "somewhat too long", $84.2 \%$ as "about right" and 2.6\% as "somewhat too short". CAG targets: Based on CAG wait time targets for iron deficiency anemia and a positive FOBT result in a newly referred patient, 14 of $30(46.7 \%)$ met their CAG targets. Eight of the 30 patients screened were patients already followed by a gastroenterologist (Figure 3).

Compared with those referred for screening colonoscopies, the wait times for those referred for iron deficiency anemia or a positive FOBT result were significantly shorter $(\mathrm{P}<0.001)$.

\section{High-impact diagnosis subgroup}

Forty-one of the 417 participants were determined by the panel of five gastroenterologists to have a high-impact diagnosis. These patients underwent various endoscopic procedures including 23 colonoscopies, 12 upper endoscopies, five flexible sigmoidoscopies and one colonoscopy plus upper endoscopy. Of the 17 participants with a documented referral, the mean wait time was 115 days and the median wait time was 113 days, with a range of nine to 365 days (Figure 1).

Impact on QOL: GI symptoms that adversely affected patient QOL while awaiting endoscopy (score of 5 or more on the seven-point Likert scale) were indicated by $26.8 \%$, $24.4 \%$ and $22 \%$ of patients with respect to degree of worry about having a serious diagnosis, GI symptoms interfering with social function and GI symptoms interfering with their ability to perform activities of daily living, respectively.

CAG targets: Among the newly referred participants who were discovered to have a high-impact diagnosis, four of $17(23.5 \%)$ met the CAG targets. Twenty-four of the 41 patients were already followed by a gastroenterologist (Figure 3).

\section{QOL and wait time}

To determine the association between QOL and wait time, three QOL variables - how worried the patient was about a serious problem, symptoms interfering with social activities and symptoms interfering with normal activities of daily living - were compared with actual participant wait times. A nonparametric correlation was employed by using actual wait times, along with three seven-level Likert response questions for QOL, to assess whether higher values of one were associated with higher or lower values of the other. Results were significant $(\mathrm{P}=0.009, \mathrm{P}<0.001, \mathrm{P}<0.001$, respectively), indicating that higher levels of worrying and interference with daily activities were associated with lower levels of waiting.

\section{DISCUSSION}

Over the past several years, improving access to Canadian health care services has been a major focus of patients, the public, governments, media and health care service providers.
Polls regularly show that Canadians are concerned about wait times and the general state of the health care system (8). In a 2005 survey (1), 19\% of patients consulting with a medical specialist reported that they faced difficulties accessing health care. Similarly, of the individuals who accessed selected diagnostic tests, $13 \%$ reported difficulties accessing care. "Waiting too long for care" was cited as the number one barrier, indicated by $65 \%$ of those surveyed who experienced difficulties. The proportion of patients who felt that their wait time was unacceptable was highest among those who waited for specialist visits (29\%) and diagnostic tests (21\%). Approximately $18 \%$ of individuals who visited a specialist indicated that waiting for the visit affected their daily life, with $71 \%$ of those affected reporting that they experienced worry, stress and anxiety by waiting for a diagnostic test.

The Fraser Institute's 16th annual waiting list survey (8) found that the Canada-wide total waiting time between referral from a general practitioner and treatment (averaged across all 12 specialties and 10 provinces surveyed) increased from 17.7 weeks in 2005 to 17.8 weeks in 2006.

In September 2004, in response to growing public concern, the federal government presented a 10 -year plan (3) to strengthen health care, calling for each jurisdiction to establish comparable indicators of access to health care professionals and evidence-based benchmarks for medically acceptable wait times. The CAG has recently developed evidence-based maximal wait time benchmarks for adult digestive disease consultation and associated diagnostic services (6).

Our study attempted to quantify wait times for GI endoscopic procedures at a tertiary care centre and correlate these with the clinical presentation, impact on QOL and final diagnosis. In addition, we compared actual wait times with CAG benchmark wait times. Based on our results, overall total wait times met CAG targets in a small proportion of patients $(21.4 \%)$, with screening colonoscopy patients faring the worst $(11.5 \%)$. Of note, the FOBT-positive or iron deficiency anemia group had a significant increase in the percentage $(46.7 \%)$ of patients meeting CAG targets. This is likely secondary to higher urgency of the complaint requiring investigation and appropriate triaging by the gastroenterologists accepting the referral.

Overall, 38.4\% of patients were not satisfied with their wait time for GI endoscopic procedures, with the majority of patients $(55.5 \%)$ awaiting screening GI endoscopic procedures not satisfied with their wait time. The level of dissatisfaction might actually be underestimated in the present study, given that patients completed their questionnaires when they arrived for their procedures. It would be of interest to determine the level of patient satisfaction at the beginning of their wait, when they are confronted with a projected procedure date that is months away. In addition, a significant number of patients waiting for GI endoscopic procedures reported impairment of various aspects of their QOL due to their ongoing GI symptoms. Our study found that approximately $20 \%$ of patients awaiting GI procedures had symptoms that affected their social functioning, which was somewhat higher than that reported in a nationwide study (1) of patients awaiting diagnostic testing (13\%). Furthermore, 41 of 417 participants in the present study had a high-impact endoscopic diagnosis that could result in significant changes in management. From this group, only $23.5 \%$ of patients met the CAG targets. Although not significant, there was a proportional trend 
toward those with a high-impact diagnosis having an aspect of their QOL adversely affected.

A potential limitation to the applicability of the present study's results is the lack of participation from the entire pool of patients that underwent endoscopy over the study period. Noncompliance was not an issue because all patients asked to complete the questionnaire were agreeable, with no reported refusals. The low number of participants compared with the total number of patients who underwent endoscopy related solely to nurse compliance in distributing the questionnaire. We have no evidence that the nurses were selective in the type of patient that was given a questionnaire. Rather, whether the questionnaire was distributed appeared to relate to time constraints within the endoscopy unit. In addition, the generalizability of the results from the tertiary care centre in the present study to the rest of Canada requires further investigation. As previous studies have found, wait times for GI consultation vary widely across Canada (7) and there could be similar wait time variation for GI endoscopic procedures.

\section{CONCLUSIONS}

The present study supports the conclusion that at a tertiary health care centre, CAG targets are being met in a relatively small proportion of patients. Patients referred for screening and surveillance procedures are less likely to meet their target wait time, suggesting that priority is being given to those with symptoms and/or a greater likelihood of having serious pathology. The observation that many of the patients not meeting wait time targets have GI symptoms that significantly impair their QOL and/or endoscopically established diagnoses of serious GI disease is concerning, and reinforces the belief that further efforts are required to improve access to digestive health care in Canada.

ACKNOWLEDGEMENTS: The authors thank Drs WT Depew, LC Hookey, MJ Ropeleski and SJ Vanner for their assistance in determining high-impact diagnoses, and the endoscopy nurses at Hotel Dieu Hospital in Kingston, Ontario, for their assistance with the present project.

\section{APPENDIX A}

\section{Questionnaire}

I am here to undergo a: colonosopy __ ; upper endoscopy __ ; flexible sigmoidoscopy __ (please check all that apply; if you are unsure, please ask the nurse)

What is the main reason why you have been referred for an endoscopic examination?

Did you have a previous procedure appointment that was missed or had to be rescheduled? (Yes/No)

How long have you been waiting for endoscopy since you initially saw a gastroenterologist? ( $<2$ weeks, $<1$ month, $<3$ months, $<6$ months, $6-12$ months, $>1$ year)

Do you think the time you had to wait for this procedure was: (far too short, somewhat too short, about right, somewhat too long, far too long)?

What do you think the maximum wait time for this procedure should have been? (no more than a few days, $<2$ weeks, $<1$ month, $<3$ months, $<6$ months)

Has your doctor told you what he/she thinks your diagnosis is? (Yes/No)

Has your doctor told you whether or not he/she thinks you have a serious problem? (Yes/No)

While waiting for this procedure, have you had ongoing digestive symptoms that have caused you to miss work or school?

(No, $<5$ days/month, 5-15 days/month, >15 days/month, unable to work, N/A)

While waiting for this procedure, how worried have you been about a serious undiagnosed disease of your digestive system? (seven-point Likert scale)

While waiting for this procedure, have you had ongoing digestive symptoms that have interfered with your ability to participate in your usual social or recreational activities? (seven-point Likert scale)

While waiting for this procedure, have you had ongoing digestive symptoms that have interfered with your ability to carry out normal activities of daily living?

(eg, preparing and eating meals, household tasks, sleeping, personal hygiene, etc) (seven-point Likert scale)

N/A Not applicable

\section{APPENDIX B}

High-impact diagnoses

\begin{tabular}{|c|c|}
\hline Indication for endoscopy & Endoscopic/pathological diagnosis \\
\hline Regurgitation & Candida esophagitis \\
\hline Dysphagia & Peptic stricture; Schatzki ring; eosinophilic esophagitis \\
\hline Dyspepsia (including nausea and vomiting) & Peptic ulcer: Helicobacter pylori-positive \\
\hline History of Barrett's esophagus (screening for dysplasia) & High-grade dysplasia (HGD) \\
\hline Colon screening/polyp surveillance & Colon cancer; polyp with HGD \\
\hline $\begin{array}{l}\text { Iron deficiency anemia; positive FOBT result; medical history of overt } \\
\text { gastrointestinal bleeding }\end{array}$ & $\begin{array}{l}\text { Colon cancer; IBD; esophageal varices/portal hypertensive gastropathy; } \\
\text { polyp with HGD }\end{array}$ \\
\hline Lower gastrointestinal symptoms (abdominal pain, diarrhea, bowel dysfunction) & Crohn's disease; microscopic/collagenous colitis \\
\hline Medical history of IBD (assessing for exacerbation) & Moderately active colitis; stricture of ileocecal valve \\
\hline
\end{tabular}

A panel of five gastroenterologists were provided with the reason for referral and gross endoscopic and pathological diagnosis. They were asked to rate the level of impact of the diagnosis with respect to the management change, whereby an intervention could change the patient's quality of life; and the impact on prognosis, using a three-point rating system (low, medium, high). FOBT Fecal occult blood test; IBD Inflammatory bowel disease 


\section{REFERENCES}

1. Statistics Canada. Access to health care services in Canada: January to June 2005. <http://dsp-psd.pwgsc.gc.ca/Collection/Statcan/82-575X/82-575-XIE.html> (Version current at June 19, 2008).

2. The taming of the queue: Wait time measurement, monitoring and management - colloquium report, March 31 to April 1, 2004. $<$ http://www.cprn.org/documents/28648_fr.pdf > (Version current at June 19, 2008).

3. Health Canada. A 10-year plan to strengthen health care, September 16, 2004. <http://www.hc-sc.gc.ca/hcs-sss/deliveryprestation/fptcollab/2004-fmm-rpm/nr-cp_9_16_2_e.html/>

(Version current at June 19, 2008).

4. Hudson AR, Glynn P. The wait time strategy, December 8, 2004. <http://www.health.gov.on.ca/transformation/wait_times/providers/ strategy/wt_strat_overview.pdf $>$ (Version current at June 19, 2008).
5. Beck IT. Disproportion of economic impact, research achievements and research support in digestive diseases in Canada. Clin Invest Med 2001;24:12-36.

6. Paterson WG, Depew WT, Paré P, et al; Canadian Association of Gastroenterology Wait Time Consensus Group. Canadian consensus on medically acceptable wait times for digestive health care. Can J Gastroenterol 2006;20:411-23.

7. Paterson WG, Barkin AN, Hopman WM, et al. Wait times for GI consultation in Canada: The patient perspective. Can J Gastroenterol 2006;20(Suppl A):58A. (Abst)

8. Esmail N, Walker MA. Waiting Your Turn: Hospital Waiting Lists in Canada, 16th edn. Fraser Institute, 2006.

$<$ www.canceradvocacy.ca/ann/special.html/4621/Fraser+Institute+W ait+Times+Report+2006.pdf $>$ (Version current at June 19, 2008). 


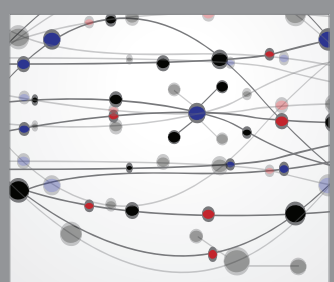

The Scientific World Journal
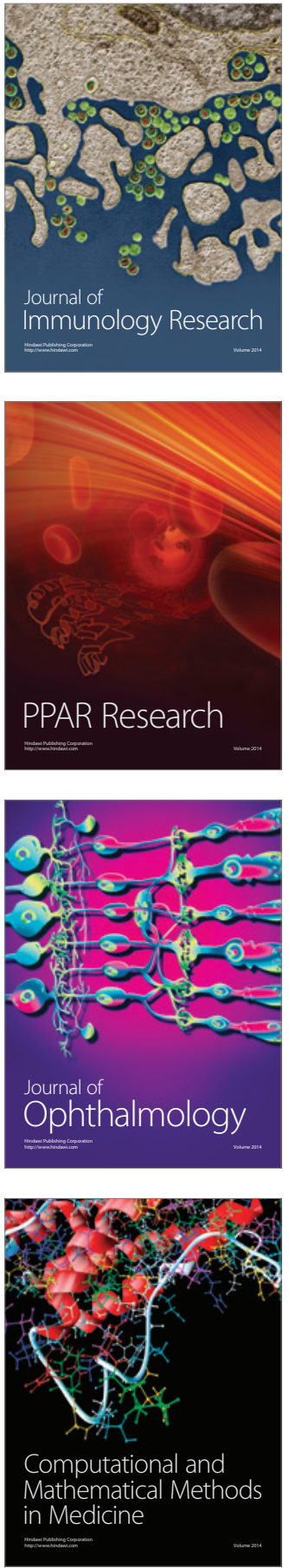

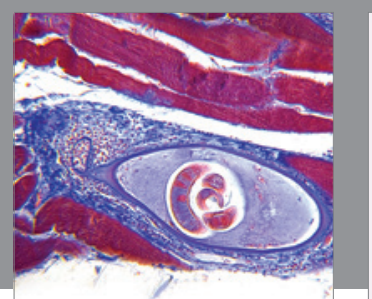

Gastroenterology Research and Practice

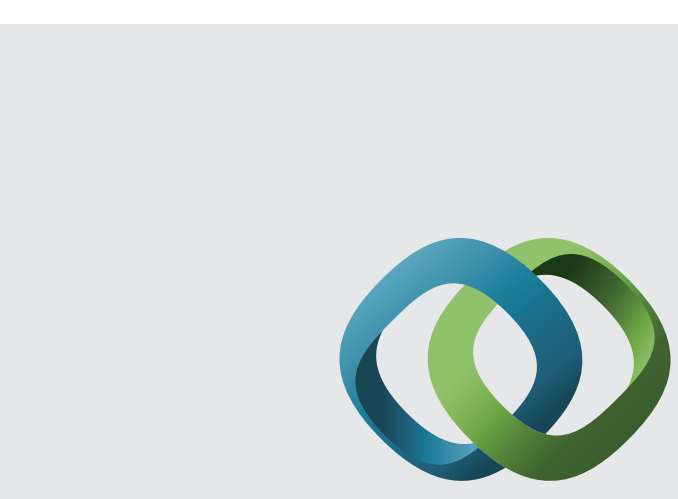

\section{Hindawi}

Submit your manuscripts at

http://www.hindawi.com
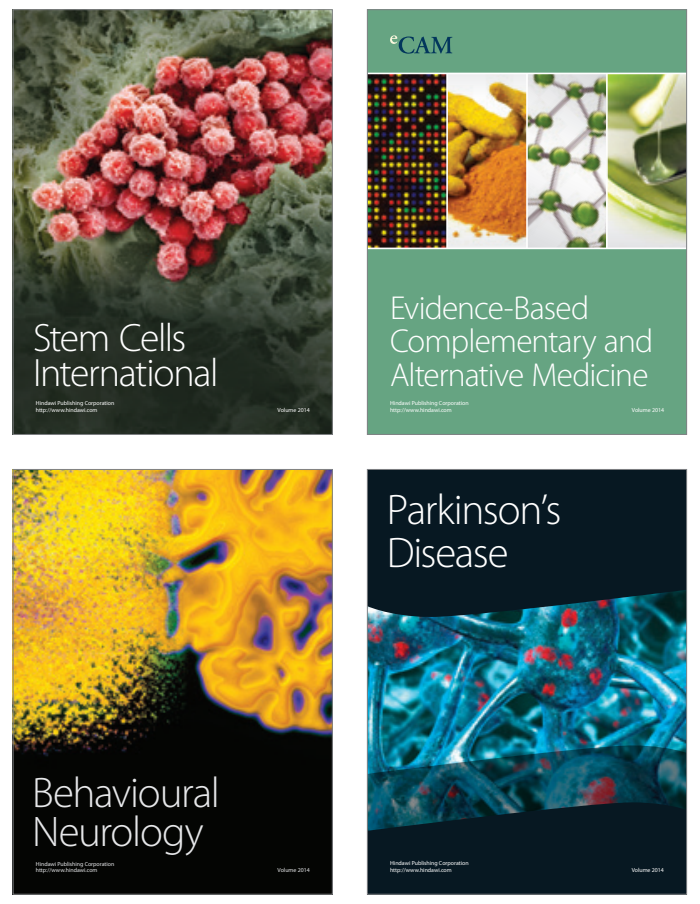
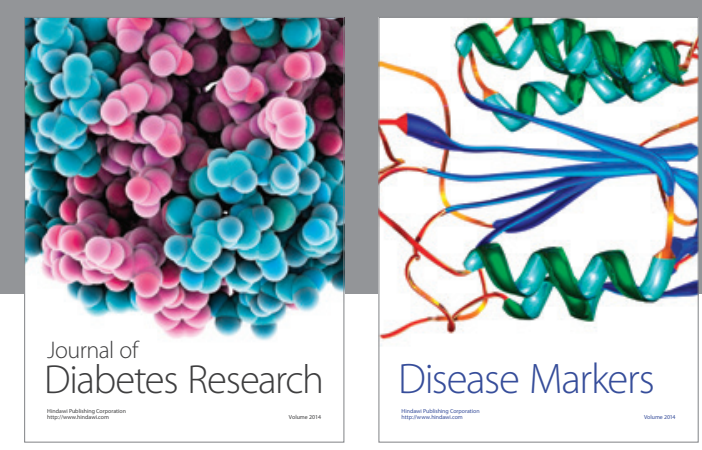

Disease Markers
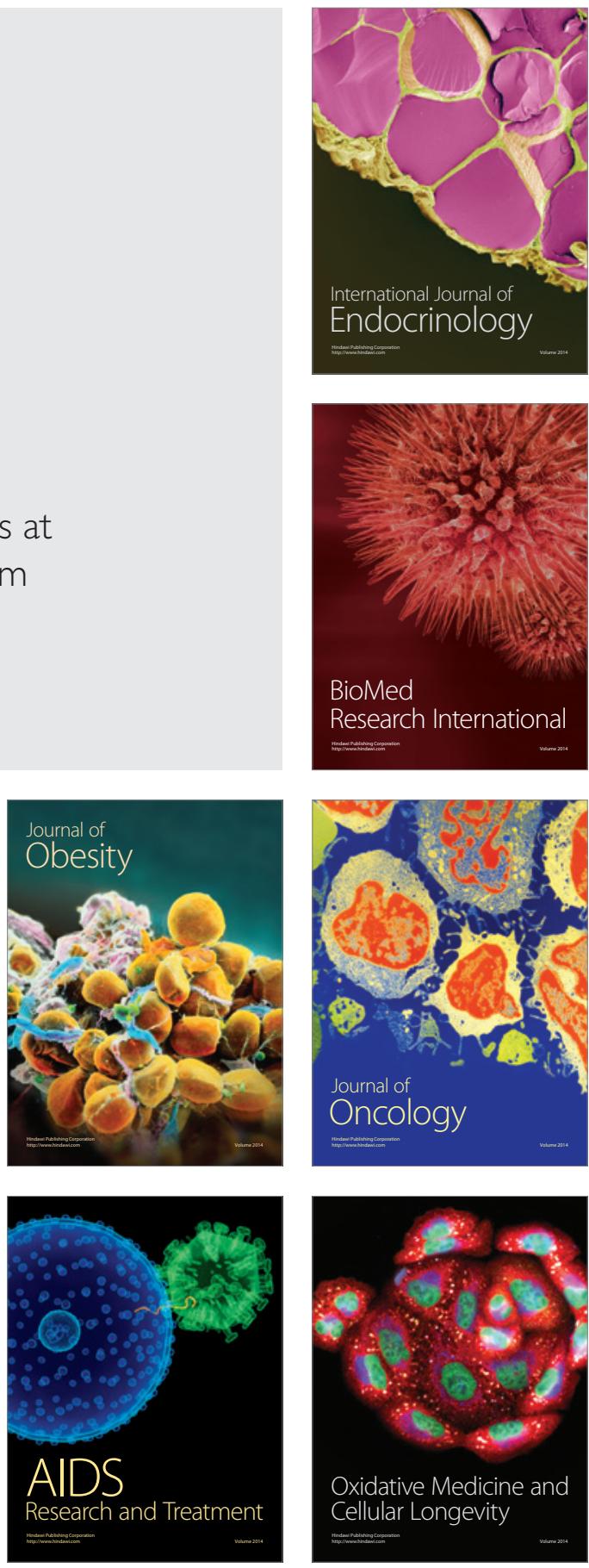